\title{
ESTRATÉGIAS DE ENFRENTAMENTO DA VIOLÊNCIA URBANA POR ATIVISTAS SOCIAIS DO RIO DE JANEIRO
}

COORDINATING STRATEGIES OF URBAN VIOLENCE BY SOCIAL ACTIVISTS FROM RIO DE JANEIRO

\section{ESTRATEGIAS DE ENFRENTAMIENTO DE LA VIOLENCIA URBANA POR ACTIVISTAS SOCIALES DE RIO DE JANEIRO}

\author{
Katerine da Cruz Leal Sonoda* \\ Simone Gonçalves de Assis ${ }^{* *}$ \\ Miriam Schenker ${ }^{* * *}$
}

\begin{abstract}
RESUMO
Este artigo investiga a participação dos sujeitos em ativismo social como fator de enfrentamento e, ou, ressignificação da violência urbana. Os objetivos específicos foram conhecer a vivência da violência urbana expressa pelos entrevistados, estudar as principais formas de enfrentamento e refletir sobre possíveis relações entre as vivências de violência na saúde. Foram realizadas catorze entrevistas com membros de quatro instituições cariocas de enfrentamento da violência urbana. A violência se mistura e influencia a história de vida dos ativistas, na qual o cotidiano e as atividades diárias foram modificados pelas experiências de violência. A maior parte dos entrevistados afirmou ter tido a saúde física e mental alterada/prejudicada. Identificou-se o uso de estratégias individuais e coletivas de enfrentamento da violência. A lógica interna do grupo aponta que a atitude de lidar com a violência é considerada como uma forma de proteção, levando à construção de estratégias de enfrentamento e, ou, redução da violência urbana.
\end{abstract}

Palavras-chave: Violência urbana. Ativismo. Saúde.

\begin{abstract}
The article investigates the subjects' participation in social activism as a factor in coping and / or redefinition of urban violence. The specific objectives were to identify the experience of urban violence expressed by respondents, study the main ways of coping, and reflect on possible relationships between the experiences of violence on health. Fourteen interviews with members of Rio de Janeiro's institutions created to help people cope with urban violence were conducted. Violence mingles with and influences activists' life storys,
\end{abstract}

\footnotetext{
Texto recebido em 21 de outubro de 2013 e aprovado para publicação em 24 de junho de 2015.

Escola Nacional de Saúde Pública Sérgio Arouca. E-mail: katerine.sonoda@gmail.com.

** Escola Nacional de Saúde Pública, Fundação Oswaldo Cruz. E-mail: sgassis@globo.com.

*** Escola Nacional de Saúde Pública, Fundação Oswaldo Cruz. E-mail: schenkerbrasil@hotmail.com.
} 
in which daily life and daily activities have been modified by experiences of violence. Most respondents said they had the physical and mental health changed / damaged. Identified the use of individual and collective strategies to combat violence. The internal logic of the group that the attitude of dealing with violence is regarded as a form of protection, leading to the construction of coping strategies and / or reduction of urban violence.

Keywords: Urban violence. Activism. Health.

\section{RESUMEN}

El artículo investiga la participación de los sujetos en el activismo social como factor de enfrentamiento y / o resignificación de la violencia urbana. Los objetivos específicos fueron conocer la experiencia de la violencia urbana expresada por los entrevistados, estudiar las principales formas de enfrentamiento y reflexionar sobre las posibles relaciones entre las experiencias de violencia en la salud. Se realizaron catorce entrevistas con miembros de cuatro instituciones cariocas vinculadas al enfrentamiento de la violencia urbana. La violencia se mezcla y está influencia la historia de vida de los activistas, donde lo cotidiano y las actividades diarias fueron modificados por las experiencias de violencia. La mayoría de los entrevistados dijeron que habían tenido la salud física y mental alterada / dañada. Fue identificado el uso de estrategias individuales y colectivas para combatir la violencia. La lógica interna del grupo señala que la actitud frente a la violencia es considerada como una forma de protección, que lleva a la construcción de estrategias de supervivencia y / o reducción de la violencia urbana.

Palabras clave: Violencia urbana. Movimientos activistas. Salud.

\section{INTRODUÇÃO}

violência urbana na cidade do Rio de Janeiro é um fenômeno relativamente
novo, datado historicamente há poucas décadas (Souza, 2008). Todavia o
medo de sofrer uma agressão ou outro crime violento não é novidade na cultura brasileira, tornando-se mais rotineiro e intenso, ganhando, nas últimas décadas, destaque na mídia, nas instituições e na vida de todo cidadão.

Este artigo investiga a participação dos sujeitos em ativismo social como fator de enfrentamento e, ou, ressignificação da violência urbana, apontando as principais formas de contraposição da violência pelos ativistas e refletindo sobre possíveis relações entre as vivências de violência e a saúde desses sujeitos. Pressupóe-se, neste artigo, que o ativismo social urbano é um instrumento de enfrentamento, apoio ou ressignificação entre pessoas que vivenciam a violência urbana. 
Souza $(2005,2006,2009)$ define ativismo social como atividade pública organizada por atores sociais, com característica de ser relativamente duradoura e pública. Abarca uma série de ações, organizaçôes e mobilizações que vão desde reivindicações pontuais (que não aprofundam ou não fazem uma crítica à sociedade instituída e se esvaziam quando o problema é resolvido) até mobilizações mais amplas, com forte potencial transformador, discurso crítico e questionamentos políticos, éticos, econômicos, estéticos, entre outros.

Em sua origem e manifestações, a violência é um fenômeno sócio-histórico e acompanha toda a experiência da humanidade. Portanto ela não é, em si, uma questão de saúde pública. Transforma-se em um problema para a área porque afeta a saúde individual e coletiva, e exige, para sua prevenção e enfrentamento, formulação de políticas específicas e organização de práticas e de serviços peculiares ao setor (Minayo, 2006). Por meio das múltiplas manifestações, a violência pode ter impacto sobre a saúde física e psíquica de quem a comete, de quem a recebe e também de quem a assiste (Minayo, 2009). Uma vez impactado, as reações de um indivíduo podem ser as mais diversas, com diferentes graus de mobilização na vida dos sujeitos (Sonoda, 2008, 2011, 2012).

Diante da violência vivida cotidianamente, diversas "estratégias" de sobrevivência comportamentais e sociais são utilizadas pelas pessoas para lidar com esse fenômeno, espraiado pelo tecido urbano da cidade.

Por violência urbana entende-se não aquela que se refere tão somente à que tem como palco a cidade, mas sim àquela violência cujas diversas manifestaçôes estão fortemente vinculadas à espacialidade urbana, que remetem a problemas como o estresse e a deterioração geral da "urbanidade" ou "civilidade" no ambiente de uma grande cidade contemporânea (Souza, 2005, 2006, 2008).

Quando se estudam as possibilidades de enfrentamento da violência, a mobilização popular se destaca nesse processo. Amaro, Andrade e Garanhani (2010) destacam que estudos feitos em diversas partes do mundo têm evidenciado que a existência da coesão social, resultado das práticas de participação comunitária, é um dos fatores de proteção mais eficazes contra a violência. Essa afirmativa pode ser verificada também nas pesquisas de Marcos (2011), Ramos (2007) e World Health Organization (2004).

A mobilização popular desperta valores que estimulam a união, a cidadania e o cultivo da paz entre os indivíduos (Souza \& Grundy, 2004), porém é um processo dinâmico e variável entre as populações (Amaro, Andrade \& Garanhani, 2010). 
Diversos estudos (Birman, 2001; Glicken, 2006; Leite \& Birman, 2004; Maciel \& Santos, 2004; Peres, 2006, entre outros) apontam possíveis efeitos para a saúde da população exposta à violência. Medo, ansiedade, depressão, transtorno de estresse pós-traumático, baixa autoestima, desconfiança, hostilidade, distúrbios do desenvolvimento, baixo rendimento escolar são alguns dos problemas que a literatura aponta como consequências da violência para a saúde mental das populações expostas. Sobre as vítimas diretas, incluem-se as lesões físicas como fraturas, desfigurações, queimaduras e abortos, além de situações clínicas crônicas, sobretudo psicossomáticas, como dor pélvica, cefaleias, síndrome do cólon irritável, fibromialgia, entre outros.

Soares, Miranda e Borges (2006) destacam ainda a questão das vítimas ocultas da violência, que são os parentes ou pessoas próximas das vítimas diretas, e sobre as quais pouco se sabe a respeito de como reagem e sentem suas perdas.

Souza (2008) enfatiza que o medo parece estar enraizado na população das grandes metrópoles violentas, provocando consequências comportamentais e psicológicas diversas. A "fobópole", um conceito cunhado e desenvolvido pelo autor, é uma cidade em que boa parte de seus habitantes sofre de estresse crônico e outras psicopatologias por causa da violência, do medo da violência e da sensação de insegurança.

Ainda no que se refere às formas possíveis de enfrentamento da violência urbana, o apoio social também se destaca como importante ferramenta. Os suportes sociais recebidos e percebidos pelas pessoas são fundamentais para a manutenção da saúde mental, visto que uma rede social fortalecida ajuda o indivíduo a enfrentar situações estressantes. Uma rede social pessoal estável, ativa e confiável protege o indivíduo em sua vida diária, favorece a construção e manutenção da autoestima e acelera os processos de recuperação da saúde. Portanto é fundamental para a promoção da saúde nos aspectos físicos, psicológicos e afetivo-emocionais (Sluzki, 1997).

Os ativismos sociais urbanos se destacam como importante ferramenta de enfrentamento da violência urbana, conforme se configuram como mediadores nas respostas à violência (Ramos, 2007), como formas de as pessoas se organizarem e se colocarem como participantes ativos da sociedade (Souza \& Rodrigues, 2004) e como alternativas concretas na solução de demandas e necessidades (Souza, 2006).

Neste artigo, foi investigado como alguns ativistas sociais da cidade do Rio de Janeiro vivenciam, reagem e lidam com a violência que sofreram ao longo de suas vidas, como vítimas (diretas ou indiretas) da violência urbana. Destaca a violência urbana circunscrita sobretudo aos territórios favelados, e à praticada por membros do tráfico de drogas de varejo, paramilitares (milicianos) e policiais. 


\section{MÉTODO}

Optou-se por trabalhar com uma amostra intencional com base na técnica "bola de neve" para selecionar os entrevistados de cada instituição (Minayo, 2008). A escolha de entrevistar membros fundadores, funcionários, gestores e professores das instituições selecionadas se justifica pelo trabalho que desempenham, participando diretamente do seu cotidiano e dos trabalhos nelas desenvolvidos.

\subsection{Participantes}

O critério de seleção dos informantes respeitou o pertencimento aos distintos cargos ocupados, à diversidade de funções (administrativas e operacionais), bem como o tempo de trabalho na instituição (pelo menos quatro anos nas instituições selecionadas) e terem sido vítimas (diretas ou indiretas) da violência urbana. Participaram do estudo 14 ativistas sociais, membros de instituiçôes cariocas de enfrentamento à violência urbana. Nos resultados, as instituições são nomeadas de A, B, C e D, visando a preservar sua identificação, e os nomes dos entrevistados foram modificados. As instituiçôes participantes foram escolhidas segundo a disponibilidade e motivação de seus gestores em participar da pesquisa, bem como o perfil das atividades desenvolvidas em cada uma delas, que se caracterizam como enfrentamento da violência urbana. Essas instituições atuam no cenário carioca há alguns anos, e o ponto em comum entre elas, além do tema da violência, está em suas histórias de fundação: todas nasceram de "tragédias" urbanas.

\subsection{Instrumentos e procedimentos}

Foram efetuadas 14 entrevistas semiestruturadas ( 9 homens e 5 mulheres, na faixa dos 22-56 anos de idade), baseadas em roteiro predefinido que abordou os seguintes temas: atividades desempenhadas na instituição, se e como a violência urbana afeta o cotidiano em suas áreas de atuação, vivências de violência urbana, eventuais problemas com traficantes de drogas, policiais e paramilitares (milícias), se e como as experiências de violência alteraram as atividades, possíveis impactos na saúde e formas de enfrentamento dessas vivências. Interrompeu-se a realização de entrevistas por meio do critério da saturação das respostas (Denzin \& Lincoln, 1994). 


\subsection{Análise dos dados}

O processamento e a interpretação dos dados qualitativos foram efetuados com base no enfoque da análise temática, seguindo a perspectiva da análise de conteúdo de Bardin (1977) em sua versão adaptada por Gomes (2010) e Minayo (2008). São propostas três etapas nesse processo: a constituição do corpus e a formulação de hipóteses, a segunda etapa, em que são geradas as categorias e, por fim, a interpretação dos resultados. As categorias que emergiram na análise, neste artigo, são: tipologia da violência; impactos na saúde física e mental dos ativistas; e formas de enfrentamento do cotidiano violento. A pesquisa foi aprovada pelo Comitê de Ética em Pesquisa da Escola Nacional de Saúde Pública/Fiocruz (número 0007.0.031.000-11).

\section{RESULTADOS}

A maioria dos ativistas (5) ocupava o cargo de coordenador/membro fundador nas instituiçôes onde exerciam suas atividades durante a etapa de campo da pesquisa. Três deles se definiram como membros das instituições em que trabalhavam, dois eram professores, dois eram supervisores, um era agente de projetos e outro, assessor. As diferenças entre os participantes das quatro instituições visitadas eram significativas no que se referia ao perfil dos ativistas (que diferia de instituição para instituição) e nas formas de enfrentamento da violência urbana.

A própria localização geográfica das instituições já dizia muito sobre as diferenças encontradas. Os ativistas que eram moradores de favelas atuavam na instituição sediada ou próxima a seu local de moradia. Parecia existir ali uma "escolha" de mão dupla, em que o ativista escolhia e era escolhido pela instituição.

$\mathrm{Na}$ instituição $\mathrm{A}$, a entrada dos ativistas ocorria de uma forma bastante peculiar. Em geral, os gestores buscavam pessoas envolvidas com a criminalidade e ofereciam oportunidade de emprego. Essa chance de "mudar de vida" era oferecida para dezenas de pessoas, porém poucas aceitavam e pouquíssimas seguiam no ativismo. De um modo geral, os ativistas na instituição A eram jovens, tinham baixa escolaridade e eram moradores de favelas. Um achado interessante foi que, nessa instituição, os entrevistados foram vítimas e também perpetradores da violência urbana. As vítimas tiveram problemas com o tráfico e com a polícia. Já os perpetradores foram traficantes de drogas e milicianos. 
$\mathrm{Na}$ instituição $\mathrm{B}$, os ativistas entrevistados, em sua maioria, tornaram-se ativistas após participarem dos cursos e oficinas oferecidos na instituição quando crianças ou adolescentes e, de alguma forma, "encantaram-se" com o trabalho desenvolvido, tornando-se militantes pela causa da instituição. Apresentavam nível educacional superior aos demais e tinham um perfil mais acadêmico. Eram jovens e moradores de favela, porém alguns eram moradores de bairros formais. Os que sofreram violência urbana foram vítimas do tráfico e, indiretamente, da polícia.

Já na instituição $C$, todos foram vítimas diretas de violência. Não ficou claro como os ativistas se conheceram ou como passaram a atuar pela mesma causa. Eles eram mais velhos, com longa história em ativismos e movimentos sociais. Tinham baixa escolaridade e eram moradores de favelas ou áreas pobres da cidade. Foram vítimas de todos os grupos armados com domínio de território: sofreram violência do tráfico, da polícia e da milícia.

Por fim, na instituição $\mathrm{D}$, assim como na $\mathrm{C}$, os ativistas formavam uma rede de vítimas para ajudar e acolher outras vítimas. O perfil socioeconômico da instituição D era muito variado, mas os gestores eram mais velhos, com escolaridade superior e moravam em áreas privilegiadas da cidade.

Ao se analisarem as estratégias coletivas de enfrentamento (que serão apresentadas adiante), observaram-se similaridades entre os ativistas das quatro instituiçôes. Já as estratégias individuais (sobretudo as de coping, que também serão apresentadas adiante) apresentavam diferenças significativas entre eles. $\mathrm{Na}$ instituição $\mathrm{A}$, os ativistas relataram usar principalmente estratégias de enfrentamento do tipo coping de evitação. Já nas outras (B, C e D), a principal estratégia era o coping do tipo direto.

\section{TIPOLOGIA DA VIOLÊNCIA SOFRIDA PELOS ENTREVISTADOS}

Como resultado principal, destaca-se que a violência urbana se misturava e influenciava a história de vida dos ativistas, que tinham seu cotidiano e suas atividades diárias modificadas pelas experiências de violência urbana. A maioria relatou ter sofrido pelo menos uma forma direta de violência (urbana), sendo que alguns participantes foram perpetradores da violência, outros foram vítimas diretas e alguns foram expectadores desse tipo de violência (ou vítimas indiretas, que assistiram a crimes, execuções, homicídios, corpos expostos ou perderam parentes próximos). 
O diagrama a seguir representa as relações estabelecidas entre os entrevistados e as instâncias de poder que interferiam em seu cotidiano.

Figura 1. Relações de conflito entre os entrevistados, a polícia, as milícias e o tráfico de drogas.

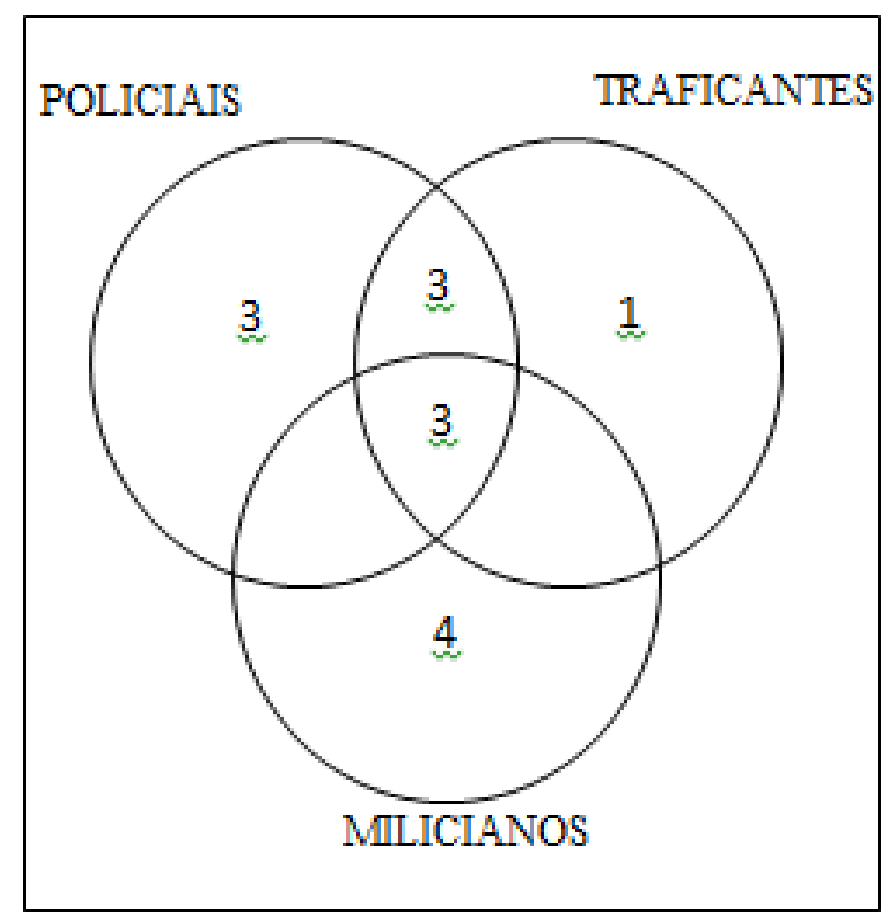

Fonte: elaborado pelas autoras

Três dos entrevistados afirmaram ter tido problemas apenas com policiais. Um teve problemas somente com traficantes de drogas e três sofreram algum tipo de violência (ameaças diretas ou veladas, surras, sequestro, entre outros) da polícia e do tráfico. Três entrevistados enunciaram ainda ter sofrido violência por parte de milicianos (paramilitares), sendo que estes últimos também relataram experiências de violência perpetradas pela polícia e pelo tráfico. Nenhum entrevistado afirmou ter tido problema apenas com milícias.

Entre os que tiveram dificuldades apenas com policiais, todos sofreram algum tipo de ameaça ou agressão direta: sequestro, extorsão, espancamento, tapa na cara, intimidação, abuso de poder e roubo. Para ilustrar, segue o depoimento de João:

Com os traficantes era de igual pra igual. E eu era o chefe. Eu fui sequestrado por vários policiais que me extorquiram dinheiro. Mas das cinco vezes que eu fui sequestrado, em duas delas eu fui espancado antes de ser negociada a minha liberdade, em troca de dinheiro. Tive cabeça quebrada, tive costas todas lanhada. E fui submetido a submarino, que é meter um plástico na sua cabeça e prender para que o ar não entre. É esse tipo de violência, sofri bastante (João, A, 37 anos). 
Outros entrevistados fizeram críticas à instituição policial, mas não tiveram problemas de ordem pessoal com policiais. Todavia relataram o incômodo gerado com as incursões desastrosas da polícia nas favelas, chacina de inocentes e desrespeito com moradores.

Outro subgrupo, composto por 3 dos 14 entrevistados, afirmou ter tido problemas com o tráfico e com a polícia. Entre eles encontram-se emboscada, espancamento, ameaças, desrespeito, "guerra" e assassinato de amigos (com relação à polícia) e "guerra", ameaça, tiros e invasão de domicílio (com relação ao tráfico de drogas). A interseção de problemas com policiais e com traficantes faz sentido porque, supostamente, a ação violenta da polícia se faz diretamente proporcional à ação violenta do tráfico de drogas. Por isso problemas com traficantes envolvem algum tipo de experiência violenta com a polícia, conforme o relato de alguns dos entrevistados.

Por fim, três entrevistados afirmaram ter tido os seguintes problemas com o tráfico, com a polícia e com milícias: ameaça, perseguição e atentado (por parte da polícia), ameaça, tiro para o alto, intimidação (dos traficantes) e ameaças, tiro no pé e atentado (por parte da milícia). Via de regra, nessa interseção (dos que tiveram problemas com policiais, traficantes e com milicianos) estão os depoimentos mais graves, as experiências mais impactantes e que foram relatadas com riqueza de detalhes. Encontram-se aqui os casos que apresentaram os maiores agravos à saúde. Entre estes depoimentos, destacou-se a fala de Paula, recheada de experiências muito chocantes, contadas com muito sofrimento e riqueza de detalhes. Paula tinha, apesar disso, uma postura de enfrentamento muito impressionante diante desses problemas:

Se eu não morri foi porque eles [grupo de extermínio] não quiseram me matar. Mas me aterrorizaram, me deram tiro no pé, me jogaram dentro do rio, me barbarizaram. Eu fiquei surda desse ouvido, eu escuto bater, mas eu não escuto bem [...] $\mathrm{O}$ traficante resolveu dizer pra mim que eu era do mesmo comando que ele. Eu disse: "Meu amor, eu não tenho comando, quem me comanda sou eu mesma, você acha que eu sou igual a você?”. E aí começou a discussão entre eu e o traficante. Ele falou assim: "Ah, quando você aparecer lá na minha área, eu vou encher sua cara de tiro, eu quero que você desça desse morro agora!". Eu falei: "Vou descer quando eu quiser, você não manda aqui". "Ou você desce agora ou eu atiro em você!". Ele atirou. "Se você atirar em mim, você vai ter que me matar". Aí ele foi e deu um tiro. [...] E aí com a polícia foram vários problemas. (Paula, C, 41 anos).

\section{VIOLÊNCIA FAZ MAL À SAÚDE: IMPACTOS NA SAÚDE FÍSICA E MENTAL DOS ATIVISTAS CARIOCAS}

No que se refere aos impactos da violência urbana na saúde, evidenciou-se um diferencial de gênero: quatro entrevistadas do sexo feminino afirmaram 
não ter tido a saúde afetada pelas experiências de violência urbana. As mulheres pareciam naturalizar mais as experiências de violência sofridas:

Vou falar coisas que eu escuto das pessoas que atuam comigo, assim, de medo de circular, de não conseguir dormir, questôes que nunca aconteceram comigo. Eu não sei se por estar exposta no cotidiano antes de atuar nesse campo, mas realmente eu não sinto. Eu tenho esse papel um pouco de conversar, de acalmar as pessoas e tentar convencê-las de que se a gente não fizer isso, a gente vai estar muito mais em risco do que fazendo (Joana, B, 32 anos).

Uma entrevistada descreveu uma situação de impotência diante das situações vividas no cotidiano e ressaltou que as condiçôes de trabalho eram muito difíceis, ela precisava se adaptar, "aprender a conviver" para desenvolver o seu trabalho. Apesar disso, afirmou que não teve a saúde prejudicada:

Uma vez, eu lembro de ter que ficar convencendo um aluno a não matar a namorada. Porque ele chegou aqui dizendo que ele ia matar a namorada, e eu fiquei conversando com ele, como se eu tivesse falando da coisa mais natural do mundo. É uma situação muito impotente, muito ruim. Eu lembro que eu saía daqui exausta. Então tiveram vezes que eu saí com febre e tal. Agora essa coisa de ter assim, a saúde alterada, eu acho que acaba que tem uma tensão, que você acaba absorvendo de alguma maneira. Acho que tem uma tensão, tem uma tensão que é de todo pacote. Mas você aprende a conviver, você tá aqui, quer fazer o trabalho e o trabalho tem essas condiçóes (Roberta, B, 36 anos).

Os demais entrevistados (10 em 14) afirmaram ter tido a saúde alterada ou prejudicada por conta da violência urbana sofrida. Os problemas de saúde estavam associados, segundo eles mesmos, às experiências vividas. Os principais sintomas, doenças e psicopatologias destacados nos relatos dos entrevistados foram ganho de peso, diabetes, pressão alta, problemas cardíacos, estresse, angústia, alcoolismo e problema renal. Para ilustrar, as falas de alguns entrevistados:

Eu sou diabética por causa desse problema que eu tive na favela de você ver as pessoas morrerem, você ver as pessoas apanharem. Eu fiquei com diabetes, nervoso por causa disso [...] (Gilda, A, 44 anos).

Eu acho que eu tenho até sequela, que às vezes eu me aborreço muito rápido. Acho que isso é um sistema nervoso muito abalado, e isso é por conta daquela vida louca. Tiroteio, de correr, de se esconder, de guerra. Administrar uma boca de fumo, que é administrar a vida dos outros (Jorge, A, 35 anos).

Eu tive uma época que eu bebi muito, engordei uns 15, 20 quilos. Mesmo que não afete fisicamente, o emocionalmente tá sempre do seu lado, caminhando ali e querendo ir pra baixo, tá sempre puxando pra baixo (Luiz, D, 54 anos). 


\section{DO LUTO À LUTA: COMO OS ATIVISTAS ESTUDADOS ENFRENTAM E ELABORAM SUAS EXPERIÊNCIAS DE VIOLÊNCIA URBANA}

Para os entrevistados, existia o momento do luto, que ocorria logo depois de sofrerem a(s) experiência(s) violenta(s), sendo o "tempo do luto" variável de pessoa a pessoa. E existia também um segundo momento, no qual eles respondiam à violência urbana (e ao seu próprio sofrimento), criando estratégias, objetivando saídas e chegando a formas de superação. $\mathrm{O}$ ativismo se configurava, assim, como uma estratégia possível de saída do sofrimento para a luta.

$\mathrm{Na}$ amostra estudada, os participantes ressignificavam a violência pelo ativismo, conferindo novos significados às suas experiências dolorosas carregadas de sofrimento. Essa ressignificação somente foi possível graças ao apoio que receberam de familiares, amigos e da própria instituição (que fundaram e, ou, tornaram-se membros militantes). Os ativistas se tornaram "protagonistas de uma causa", e o ativismo configurou-se em suas vidas como uma forma de empoderamento. Por essa atividade, eles receberam gratificação e reconhecimento da "comunidade", da família e dos seus pares, passaram a participar de uma rede e tornaram-se pessoas públicas. Esses fatores podiam ajudar na melhoria da qualidade de vida, contribuir significativamente na prevenção da doença e promoção da saúde e ainda favorecer ganhos de autonomia.

As "estratégias de enfrentamento" encontradas nos relatos foram subdivididas e categorizadas em estratégias individuais e coletivas. Alguns participantes tinham diversas formas de enfrentamento, algumas vezes agregando estratégias individuais e coletivas. $O$ quadro a seguir resume as categorias de análise encontradas:

Quadro 1. Categorias de análise: estratégias de enfrentamento da violência urbana utilizadas pelos entrevistados

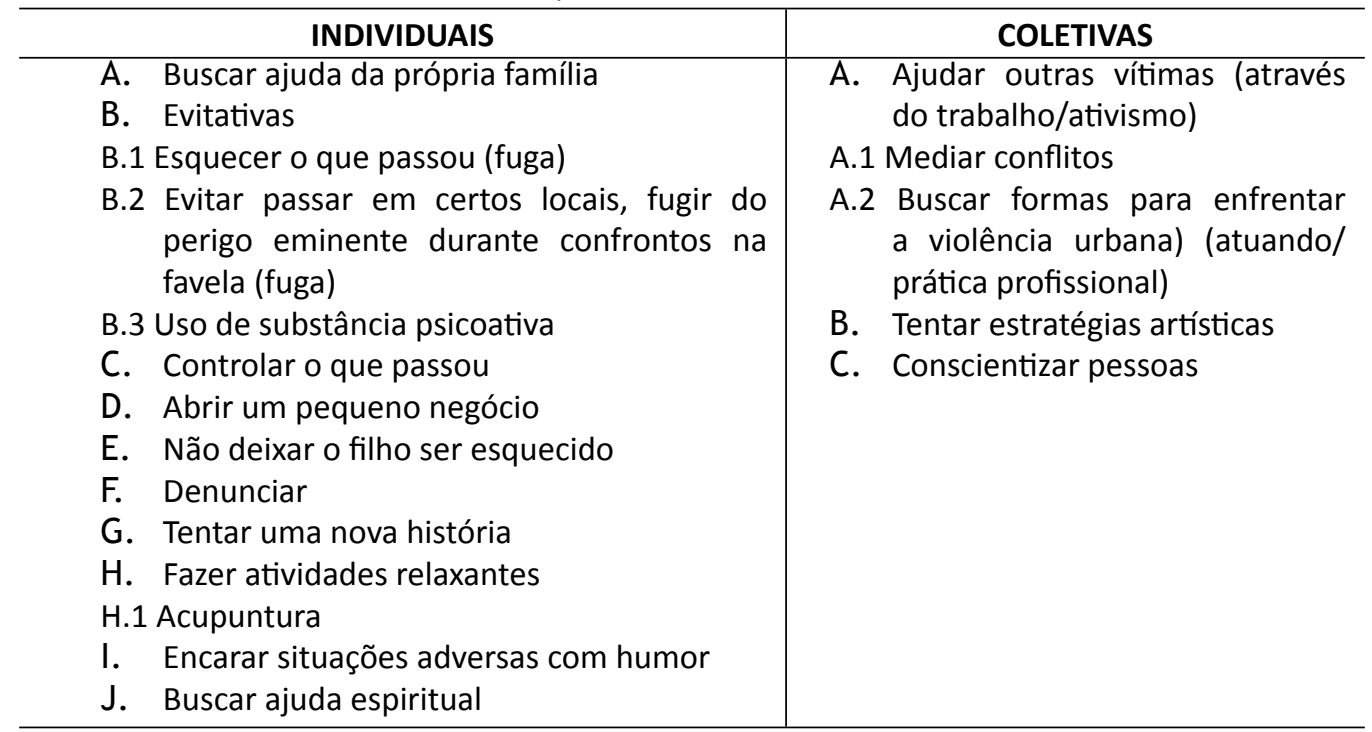

Fonte: elaborado pelas autoras. 
No que se refere às estratégias de enfrentamento da violência urbana, a maioria (9 em 14) apontou que a principal estratégia utilizada era o trabalho que desenvolvia atualmente para ajudar outras pessoas. Além disso, foram encontradas também categorias individuais de enfrentamento, como buscar ajuda na própria família, fazer atividades relaxantes, denunciar os agressores, encarar situações adversas com humor, entre outras.

Entre as estratégias individuais, apareceram nos relatos formas de elaboração das situações vividas que se configuram em "válvulas de escape" para amenizar o impacto das experiências violentas. Há aqui uma coincidência importante com estratégias de coping (formas de lidar com as dificuldades) encontradas na literatura (Glicken, 2006; Gazzaniga \& Heatherton, 2005; Assis, Pesce \& Avanci, 2006).

\section{DISCUSSÃO}

A lógica interna do grupo pesquisado aponta que a atitude de lidar com a violência levou à construção de estratégias de enfrentamento e à incorporação de estratégias de atuação profissional que visam à redução da violência urbana.

$\mathrm{O}$ ativismo surgiu na vida dos entrevistados como uma forma diferenciada de se contrapor à violência urbana, ressignificando as experiências sofridas. Tanto o ativismo quanto a própria trajetória de vida podem ser considerados meios de ressignificação, proteção e formas criativas de lidar com experiências potencialmente traumáticas. $\mathrm{O}$ "dar de si”, tão característico das pessoas engajadas em ativismos sociais, é, para o grupo pesquisado, ajudar aos outros e ajudar a si mesmo.

O ativismo é, para o grupo pesquisado, uma forma de proteção psíquica contra a violência urbana e seus efeitos na saúde. Já no que se refere às formas de proteção sociais, para a maioria dos entrevistados, o ativismo proporcionou reconhecimento público, empoderamento, liberdade de frequentar diferentes favelas (entre outros fatores), configurando uma forma de proteção social contra a violência urbana. Para outros, contudo, o ativismo faz com que socialmente eles estejam tão ou mais expostos à violência urbana quanto na época em que tiveram a experiência violenta. É o caso daqueles ativistas que tentam mediar conflitos entre a polícia e o tráfico ou entre facçôes rivais do tráfico de drogas. $\mathrm{O}$ que chama a atenção nesse subgrupo é o fato de eles continuarem lutando por uma causa que os expõe a perigo constante.

Sobre confluência das formas de violência urbana, os resultados obtidos corroboram com a literatura nacional no que se refere à violência policial, de 
traficantes e de milicianos. A polícia é apontada como agente principal da violência (Minayo, 1999,; Costa, 2004). Ao mesmo tempo, Constantino (2008) aponta que os mesmos homens que matam e ferem no exercício do seu trabalho, por vezes, no estrito cumprimento do dever e, por outras, por nítida arbitrariedade, são os mesmos que são feridos e mortos. Os policiais aparecem, assim, como algozes e vítimas da violência urbana. Os milicianos e os traficantes de drogas são apontados sobremaneira na literatura como perpetradores da violência (Alves, 2008; Cano, 2008; Silva, Fernandes \& Braga, 2008). Na amostra pesquisada, contudo, os ativistas entrevistados que atuaram no passado como traficantes ou milicianos e praticaram inúmeros atos de violência apresentam intenso sofrimento psíquico e podem ser considerados também como "vítimas" dessa violência porque, enquanto foram "fora da lei", sofreram as consequências e os riscos dessa marginalidade. As marcas das "guerras" que participaram estão em seus corpos e em suas mentes. Assim, quando se fala sobre violência, não é possível estabelecer uma dicotomia entre vítima e perpetrador. Essa problemática não foi um objetivo desta pesquisa, sendo necessário realizar um aprofundamento desse tema. Também não foi efetuada uma busca em trabalhos internacionais sobre vítimas e autores da violência.

Ainda no que se refere ao pressuposto desta pesquisa, um aspecto importante diz respeito à tríade: ativismo, violência urbana e saúde. A relação entre violência e saúde já é consagrada na literatura especializada, na qual há uma associação entre vivência de violência e apresentação de sintomas psicológicos e psiquiátricos (Gomes, 1997, 1998; Krug, Dahlberg, Mercy, Zwi \& Lozano, 2002; Minayo, 2005, 2009), manifestando-se com clareza no grupo de ativistas investigado.

Já a relação entre ativismo e promoção ou recuperação da saúde é mais difícil de estabelecer. $\mathrm{Na}$ amostra pesquisada, o ativismo surge na vida dessas pessoas num momento em que o contato com a violência parece um pouco menor, contribuindo para a busca de uma saúde mental menos submetida às pressões de vida ou morte (podendo se configurar como forma de proteção). No grupo pesquisado, os entrevistados parecem cuidar melhor da saúde após terem se tornado ativistas. No grupo composto por ex-milicianos e ex-traficantes de drogas, essa melhoria das condições e cuidados com a saúde é bastante evidente. Enquanto levavam uma "vida bandida", a saúde não era uma preocupação, e eles somente perceberam o problema quando foram presos ou quando saíram da boca de fumo e "puderam" olhar para si próprios.

Era atividade o tempo todo [...] depois de um certo tempo, essa aceleração minha, essa aceleração toda não permitia de eu ver o que tava acontecendo com o meu corpo. Depois que eu fui preso e fiquei quatro anos preso, eu comecei a perceber que a carapaça, este corpo tava começando a definhar e já tinha surgindo problemas (Geraldo, A, 41 anos). 
Também no grupo composto por vítimas diretas da violência, a atividade de militância pareceu contribuir com maiores cuidados com a saúde, principalmente psíquica, porque o ativismo configurou-se em suas vidas como um suporte que ajudou na elaboração do luto.

Corroborando resultados de outras pesquisas (Araújo, 2005; Flach, 1988; Minayo, 2009; Peres, 2006; Sonoda, 2011; Souza \& Minayo, 2005), concluiuse que a violência afeta diretamente a saúde humana. Pode-se inferir, com base na análise efetuada, que as doenças/psicopatologias/mal-estar/sintomas encontrados nos relatos dos participantes transcendem o orgânico, o psíquico e o somático: são também da ordem do "social" (uma condição socioespacial que repercute na saúde). Foi possível concluir que a saúde mental é especialmente comprometida pelas experiências de violência urbana. A associação da saúde mental com a violência urbana é direta e visível. Quanto à saúde física, essa relação entre as experiências violentas e as alterações de saúde não podem ser correlacionadas tão diretamente porque não foi investigada a história pregressa dos entrevistados, não sendo possível afirmar se esses efeitos "no corpo" já estavam comprometidos antes do início do trabalho de militância. É preciso apontar aqui que saúde mental e saúde física estão intrinsecamente relacionadas e parece muito claro que alteraçôes ou impactos em uma ou outra atingem o indivíduo globalmente.

No que se refere às estratégias desenvolvidas para lidar com os problemas enfrentados pelos ativistas cariocas, conclui-se que todos utilizam várias estratégias ao mesmo tempo. A forma de encarar varia de pessoa para pessoa e até em uma mesma pessoa. Assis, Pesce e Avanci (2006) reconhecem que, embora cada indivíduo disponha de um acervo de estratégias para enfrentar dificuldades, em geral, ele opta por alguma e se habitua a utilizá-la. Existe, assim, certa estabilidade na utilização dos estilos de coping pelas pessoas. As mesmas autoras pontuam ainda que a utilização das estratégias de coping tem a função de regular o estado emocional que acompanha o estresse e atuar diretamente na situação que o originou. No grupo investigado nesta pesquisa, puderam ser observadas estratégias de enfrentamento direto e de fuga (que pertencem ao grupo da categoria descrita nos resultados como categorias individuais) bem como estratégias de enfrentamento coletivas, que estão diretamente ligadas à instituição de origem e à rede de apoio social (Igreja, família e comunidade) que os ativistas dispõem. Encontraram-se tanto o enfrentamento ativo e direto das dificuldades causadas pelos eventos estressantes quanto formas de evitação envolvidas no gerenciamento das emoções.

Indagados sobre como superaram os problemas, os ativistas apontaram como principal estratégia ajudar outras vítimas de violência por meio do trabalho militante desenvolvido nas instituições. $\mathrm{O}$ trabalho de mediar conflitos e buscar 
formas para enfrentar a violência urbana foi a principal estratégia coletiva de enfrentamento descrita pelo grupo, seguido de estratégias para conscientizar pessoas e desenvolver atividades artísticas na instituição (blog, bloco de carnaval, grupos de dança, equipes esportivas, oficinas de arte, entre outras).

Quando o foco recai sobre as estratégias individuais de enfrentamento dos problemas decorrentes da violência urbana, corroborando estudo realizado por Assis et al. (2006), o primeiro e mais fundamental é o sentimento de apoio da família, de Deus e, especificamente entre os ativistas, o apoio institucional das organizações onde atuam. As estratégias individuais de enfrentamento da violência urbana puderam ser divididas entre as do tipo coping direto e coping de evitação. As primeiras se referem a comportamentos em que o indivíduo reage ativamente para tentar dar sentido às experiências que viveu e buscar "justiça", surgindo nos relatos como: denunciar (no caso a polícia e os traficantes às autoridades competentes), construir uma nova história, fazer atividades relaxantes e prazerosas, e enfrentar com humor as situaçōes adversas. Foi possível também observar, no mesmo grupo, comportamentos de evitar os problemas, apontados na literatura como coping de evitação, configurando-se em um adiamento de resolução do conflito. Entre as estratégias desse tipo, surgiram principalmente: tentar esquecer o que passou, evitar passar em certos locais, uso de drogas para relaxar/esquecer os problemas e abrir um pequeno negócio (para tentar se distrair e não pensar no que vivenciou).

Para finalizar, destacam-se algumas limitaçôes do estudo desenvolvido, tais como a falta de análise que especifique as diferenças de gênero, de local de moradia dos ativistas (moradores e não moradores de favelas) e de idade. Parecem ser diferenciados também os impactos na saúde e nas formas de enfrentamento quando se analisam os ativistas separadamente, como agressores, vítimas diretas ou parentes de vítima. 


\section{REFERÊNCIAS}

Alves, J. C. S. (2008). Milícias: mudanças na economia política do crime no Rio de Janeiro. In Justiça Global (Org.), Segurança, tráfico e milícias no Rio de Janeiro. Rio de Janeiro: Justiça Global, Fundação Heinrich Böll.

Amaro, M. C., Andrade, S. \& Garanhani, M. (2010). A violência sob o olhar de lideranças comunitárias de Londrina, Paraná, Brasil. Revista Saúde e Sociedade, 19(2), 302-309.

Araújo, F. A. (2005). Práticas de luto reivindicativas de justiça: a experiência das Mães de Acari. Caderno e Saúde Coletiva, 10(2), 409-418.

Assis, S. G., Pesce, R. P. \& Avanci, J. Q. (2006). Resiliência: enfatizando a proteção dos adolescentes. Porto Alegre: Artmed.

Bardin, L. (1977). Análise de conteúdo. Lisboa: Persona.

Birman, J. (2001). Mal-estar na atualidade: a psicanálise $e$ as novas formas de subjetivação. (3a ed.) Rio de Janeiro: Civilização Brasileira.

Cano, I. (2008). Seis por meia dúzia? Um estudo exploratório do fenômeno das chamadas "milícias" no Rio de Janeiro. In Justiça Global (Org.), Segurança, tráfico e milícias no Rio de Janeiro. (pp. 48-83). Rio de Janeiro: Justiça Global, Fundação Heinrich Böll.

Constantino, P. (2008). Percepção de risco e vitimização de policiais civis: estudo comparativo nas cidades do Rio de Janeiro e Campos dos Goytacazes. Perspectivas, 5, 112-130.

Costa, A. T. M. (2004). Entre a lei e a ordem: violência e reforma nas polícias do Rio de Janeiro e Nova York. Rio de Janeiro: FGV.

Denzin, N. \& Lincoln, Y. (1994). Handbook of qualitative research. Thousand Oaks: Sage.

Flach, F. (1988). Resiliência: a arte de ser flexivel. Rio de Janeiro: Saraiva.

Gazzaniga, M. \& Heatherton, T. (2005). Ciência psicológica: mente, cérebro e comportamento. Porto Alegre: Artmed.

Glicken, M. (2006). Learning from resilient people: lessons we can aplly to counseling and psychotherapy. California: Sage. 
Gomes, R. (1997). A violência social em questão: referenciais para um debate em saúde pública. Revista Latino-Americana de Enfermagem, 5(2), 93-99.

Gomes, R. (1998). Dadenúnciaàimpunidade: um estudo sobre morbimortalidade de crianças vítimas de violência. Cadernos de Saúde Pública, 14(2), 301-311.

Gomes, R. (2010). Análise e interpretação de dados de pesquisa qualitativa. In: M. C. S. Minayo, (Org.). Pesquisa social: teoria, método e criatividade. Petrópolis: Vozes.

Krug, E. G., Dahlberg, L. L., Mercy, J. A., Zwi, A. B. \& Lozano, R. (2002) (Eds.) Worl report on violence and health. Geneva: World Health Organization.

Leite, M. P. \& Birman, P. (Orgs.). (2004). Um mural para dor: movimentos cívicoreligiosos por justiça e paz. Porto Alegre: Editora da UFRGS.

Maciel, M. G. \& Santos, L. O. (2004). Novas configurações subjetivas: um estudo sobre o pânico e a depressão. Cadernos Saúde Coletiva, 12(1), 41-55.

Marcos, L. R. (2011). Superar la adversidad. Madrid: Booket.

Minayo, M. C. S. (1999). Fala galera: juventude, violência e cidadania no Rio de Janeiro. Rio de Janeiro: Garamond.

Minayo, M. C. S. (2005). Violência: um problema para a saúde dos brasileiros. Série B: textos básicos de saúde. Ministério da Saúde: Brasília.

Minayo, M. C. S. (2006, abril-junho). A inclusão da violência na agenda da saúde: trajetória histórica. Ciência e Saúde Coletiva, 11(2), 375-383.

Minayo, M. C. S. (2008). Desafio do conhecimento: pesquisa qualitativa em saúde. (11a ed.). São Paulo: Hucitec, Abrasco.

Minayo, M. C. S. (2009). Conceitos, teorias e tipologias de violência: a violência faz mal à saúde individual e coletiva. In K. Njaine, S. G. Assis \& P. Constantino, (Orgs.), Impactos da violência na saúde. (pp. 21-42, Vol. 2). Rio de Janeiro: Fiocruz-EAD/Ensp.

Peres, M. F. T. (2006) Violência e saúde no Brasil. In M. F. Mello, R. A. Bressan, S. B. Andreoli \& Mari, J. J. Transtorno de estresse pós-traumático: diagnóstico e tratamento. São Paulo: Manole.

Ramos, S. (2007). Respostas brasileiras à violência e novas mediações: o caso do Grupo Cultural AfroReggae e a experiência do projeto Juventude e Polícia. Ciência e Saúde Coletiva, 11 (suplemento), 1303-1311. 
Silva, J. S., Fernandes, F. L. \& Braga, R. A. W. (2008). Grupos criminosos armados com domínio de território. In Justiça Global (Org.), Segurança, tráfico e milícias no Rio de Janeiro. (pp. 16-24). Rio de Janeiro: Justiça Global, Fundação Heinrich Böll.

Sluzki, C. (1997). A rede social na prática sistêmica: alternativas terapêuticas. São Paulo: Casa do Psicólogo.

Soares, G. D., Miranda, D. \& Borges, D. (2006) As vítimas ocultas da violência na cidade do Rio de Janeiro. Rio de Janeiro: Civilização Brasileira.

Sonoda, K. C. L. (2008). Violência urbana, psicopatologias e doenças psicossomáticas. In Anais da 30 Jornada de Iniciação Cientifica, Artística e Cultural da UFRJ, Rio de Janeiro.

Sonoda, K. C. L. (2011). Efeitos da violência urbana na saúde mental de líderes comunitários no Rio de Janeiro: desafios para a saúde coletiva. In Anais do 7 Congresso Norte e Nordeste de Psicologia, Salvador.

Sonoda, K. C. L. (2012). Liderança muito perigosa: relatos de líderes comunitários vítimas da violência urbana no Rio de Janeiro. Revista Epos, 3, 1-21.

Souza, E. M. \& Grundy, E. (2004). Promoção da saúde, epidemiologia social e capital social: inter-relações e perspectivas para a saúde pública. Cadernos de Saúde Pública, 20(5), 1354-1360.

Souza, E. R. \& Minayo, M. C. (Orgs.). (2005). Impacto da violência na saúde dos brasileiros. Brasília: Ministério da Saúde.

Souza, M. L. (2005). O desafio metropolitano: a problemática socioespacial nas metrópoles brasileiras. (2a ed.). Rio de Janeiro: Bertrand Brasil.

Souza, M. L. (2006). A prisão e a Ágora: reflexōes em torno da democratização do planejamento e da gestão das cidades. Rio de Janeiro: Bertrand Brasil.

Souza, M. L. (2008). Fobópole. Rio de Janeiro: Bertrand Brasil.

Souza, M. L. (2009). “Território” da divergência (e da confusão): em torno das imprecisas fronteiras de um conceito fundamental. In M. A., Saquet \& E. S., Sposito, (Org.), Territórios e territorialidades: teorias, processos e conflitos. (pp. 57-72). São Paulo, Presidente Prudente: Expressão Popular.

Souza, M. L. \& Rodrigues, G. B. (2004). Planejamento urbano e ativismos sociais. São Paulo: Unesp. 
World Health Organization. (2004). Preventing violence: a guide to implementing the recommendations of the World Report on Violence and Health. Geneva: WHO. 